\title{
Effects of Fluorine Plasma Treatment on the Electronic Structure of Plasma-Enhanced Atomic Layer Deposition $\mathrm{HfO}_{2}$
}

\author{
W. J. Maeng, J. Y. Son, and Hyungjun Kim ${ }^{*, z}$ \\ Department of Materials Science and Engineering, Pohang University of Science and Technology
}

(POSTECH), Pohang 790-784, Korea

We investigated the effects of fluorine treatments on the electrical properties and electronic structures of plasma-enhanced atomic layer deposition $\mathrm{HfO}_{2}$ gate oxides, depending on the treatment process. Pre- and postoxide-deposition fluorine treatments were carried out using $\mathrm{CF}_{4}$ plasma. Improved dielectric properties were achieved by predeposition treatment, while degradation of electrical properties was observed for postdeposition treatment. Based on the electronic structure analysis using X-ray photoemission spectroscopy and near-edge X-ray absorption fine structures, we found that the enhanced dielectric properties of the pretreated $\mathrm{HfO}_{2}$ are induced by the defect passivation and conduction-band offset increase.

(C) 2009 The Electrochemical Society. [DOI: 10.1149/1.3089976] All rights reserved.

Manuscript submitted August 31, 2008; revised manuscript received November 16, 2008. Published March 12, 2009.

Generally, the incorporation of $\mathrm{F}$ atoms improves the electrical properties of gate oxides and reliability of the metal-oxidesemiconductor (MOS) field effect transistors by passivating oxygen vacancy states and Si dangling bonds at the Si-oxide interface. ${ }^{1,2}$ It was reported that the $\mathrm{F}$ concentration profile should be carefully controlled to enhance the gate-oxide properties. ${ }^{3}$ One report has shown that $\mathrm{F}$ can reduce the gate leakage currents, ${ }^{4}$, while another has shown the opposite results. ${ }^{5}$ Thus, to obtain good dielectric properties, optimum $\mathrm{F}$ incorporation and adequate sequence of $\mathrm{F}$ treatment are required, in which the role of $\mathrm{F}$ incorporation must be understood.

F incorporation into gate oxides has been carried out by various methods. F atom implantation was used in an early study, but implanting $\mathrm{F}$ was shown to cause uncontrolled oxide regrowth during the gate-stack process. ${ }^{6}$ As an alternative, high-temperature $F_{2}$ annealing or UV-assisted $\mathrm{F}_{2}$ annealing was reported to result in effective incorporation of $\mathrm{F}^{3,7}$ More recently, $\mathrm{F}$ treatment using highly reactive radicals from $\mathrm{CF}_{4}$ plasmas was reported on the $\mathrm{HfO}_{2}$ gate oxide prepared by sputtering. ${ }^{4,8}$ This method is especially preferable for the $\mathrm{F}$ treatment of high- $k$ films prepared by a deposition technique using plasma such as plasma-enhanced atomic layer deposition (PE-ALD), because F treatment can be carried out in situ inside of the deposition chamber.

It was reported that the high bonding strength of metal-F is responsible for the low dielectric constant caused by reduced resonance frequency of the dipole and excess $\mathrm{F}$ is responsible for the higher leakage currents due to the gap-state creation. ${ }^{5,10}$ However, detailed studies on the electronic structure for F-treated $\mathrm{HfO}_{2}$ depending on the $\mathrm{F}$ treatment process are not available. Defect states and electronic structures are important, because the physical properties such as leakage currents are closely related to them. Previously, the electronic structure on F-incorporated dielectric thin films was theoretically investigated, ${ }^{5,11,12}$ while experimental studies have been rare. In this report, we studied the electrical properties of PEALD $\mathrm{HfO}_{2}$ gate oxide treated by $\mathrm{CF}_{4}$ plasma. Especially, for F-treatments before and after $\mathrm{HfO}_{2}$ deposition, the electronic structures of $\mathrm{HfO}_{2}$ thin films were comparatively investigated using synchrotron analysis techniques, including X-ray photoemission spectroscopy (XPS) and near-edge X-ray absorption fine structures (NEXAFS).

\section{Experimental}

Tetrakis(dimethylamino)hafnium was used as a $\mathrm{Hf}$ precursor with oxygen plasma as a reactant for the total growth cycles of 30 , resulting in about $4 \mathrm{~nm}$ thickness. Details on the $\mathrm{HfO}_{2}$ PE-ALD process can be found in our previous report. ${ }^{13}$ For this study, the $\mathrm{F}$

\footnotetext{
* Electrochemical Society Active Member.

zz-mail: hyungjun@postech.ac.kr
}

treatments were carried out using $\mathrm{CF}_{4}$ plasma at a separate inductively coupled plasma reactive ion etching chamber, but the treatment can also be done in situ in the PE-ALD chamber. Pre- and postdeposition $\mathrm{F}$ treatments were carried out at the same exposure conditions with the plasma power of $50 \mathrm{~W}$ at $10 \mathrm{mT}$ Torr without chuck bias. The impurity contents and chemical binding structures were analyzed by XPS with a synchrotron radiation in the Pohang Accelerator Laboratory. The valence and conduction-band structures were studied by XPS and NEXAFS O $\mathrm{K}_{1}$ spectra at the same utility. The photon energy was changed by monochromator with detecting species for more precise measurement. The $\mathrm{Hf} 4 \mathrm{f}$ and $\mathrm{F}$ 1s corelevel spectra were measured for each sample at photon energies of 350 and $650 \mathrm{eV}$. Also, the valence-band spectra were observed at $350 \mathrm{eV}$. O K 1 NEXAFS spectra were measured by a photon beam of $520-570 \mathrm{eV}$. Spectra were acquired in normal emission geometry $\left(90^{\circ}\right.$ takeoff angle). To correct the energy shifts of the monochromator, gold film was used as a reference sample. The valence-band data have been fitted using Gaussian peaks.

For electrical measurements, MOS capacitors with dc-sputtered $\mathrm{Ru}$ as an electrode were fabricated on p-type (boron, 5 $\left.\times 10^{14} / \mathrm{cm}^{3}\right) \mathrm{Si}(001)$ substrates. The electrode was defined by patterned metal hard mask with a radius of $150 \mu \mathrm{m}$. Postdeposition annealing and forming gas annealing were carried out at $400^{\circ} \mathrm{C}$ for $10 \mathrm{~min}$ in oxygen environment and for $30 \mathrm{~min}$ in $\mathrm{H}_{2} 5$ atom \%- $\mathrm{N}_{2}$ 95 atom \%, respectively. Capacitance-voltage and current-voltage characteristics were determined using a Keithley 4200 semiconductor parameter analyzer with an HP4284 LCR meter. The midgap interface state density $\left(D_{\mathrm{it}}\right)$ was determined by a conductance method carried out at various frequencies from $1 \mathrm{kHz}$ to $1 \mathrm{MHz}$.

\section{Results}

First, we determined optimum $\mathrm{F}$ treatment time by carrying out electrical measurements for the pre-F samples (predeposition F-treated samples) with different plasma treatment times. For this, bare $\mathrm{Si}$ substrates were exposed to $\mathrm{CF}_{4}$ plasma in the time range of $15-90 \mathrm{~s}$ prior to $\mathrm{HfO}_{2}$ PE-ALD. Up to $60 \mathrm{~s}$ of plasma treatment time, the capacitance equivalent thickness (CET) value remained constant at $1.23 \mathrm{~nm}$, while it was significantly increased to $1.42 \mathrm{~nm}$ Here, CET is defined as CET $=\varepsilon_{\text {vac }} \times\left(\varepsilon_{\mathrm{SiO}_{2}} / C_{\text {acc }}\right)$, where $C_{\text {acc }}$ is accumulation capacitance, $\varepsilon_{\mathrm{SiO}_{2}}$ is dielectric constant of $\mathrm{SiO}_{2}$, and $\varepsilon_{\text {vac }}$ is dielectric constant of vacuum. Also, the lowest $D_{\text {it }}$ value was obtained for $60 \mathrm{~s}$ with small hysteresis. Based on these results, the comparison between the pre-F and post-F (postdeposition F-treated sample) was carried out for the samples treated for $60 \mathrm{~s}$. The CET difference depending on plasma treatment time is related to the reduction of dielectric constant and the change of interfacial-layer thickness. It was reported that the high bonding strength of metal-F is responsible for the low dielectric constant caused by the reduced resonance frequency of dipole. ${ }^{10} \mathrm{~A}$ previous study has shown that the dielectric constant is not affected if a suitable amount of $\mathrm{F}$ atoms 

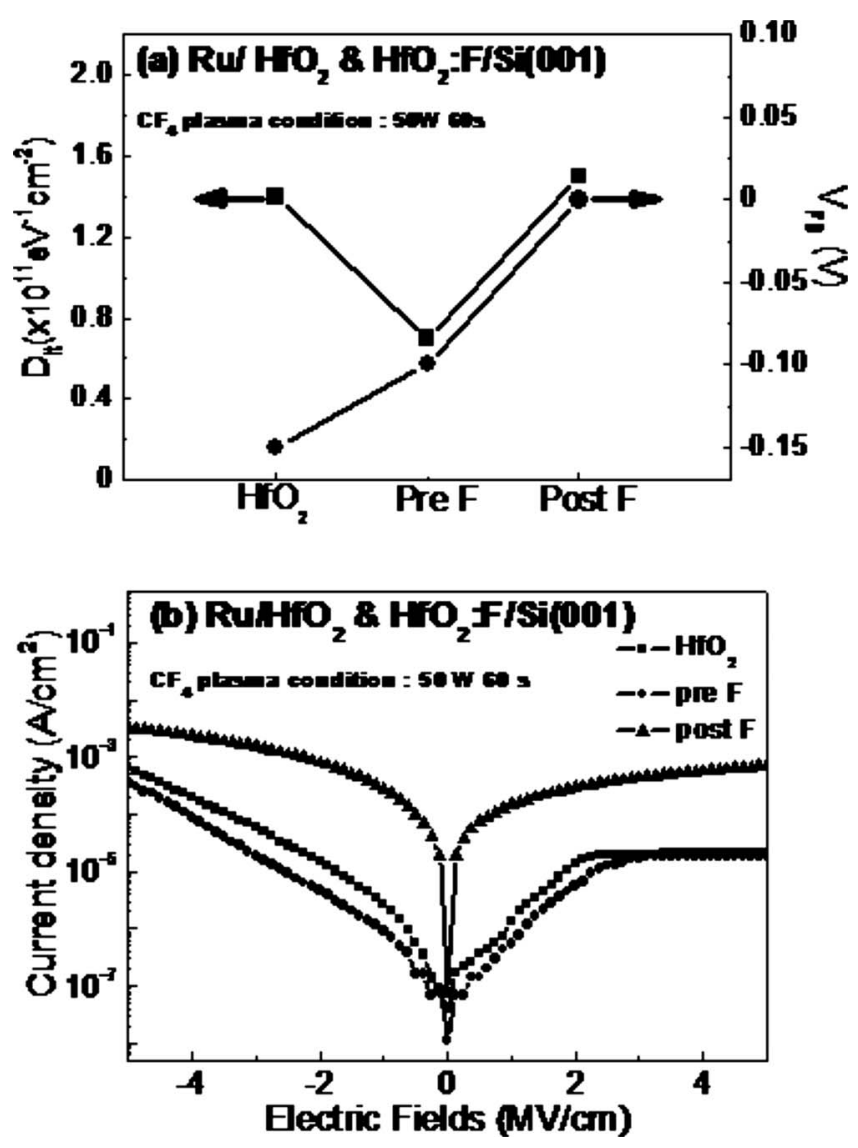

Figure 1. (a) The interface state densities and flatband voltage of MOS capacitors with $\mathrm{HfO}_{2}$ and fluorine-treated $\mathrm{HfO}_{2}$ as a gate insulator. (b) Current-voltage curves of MOS capacitors with $\mathrm{HfO}_{2}$ and fluorine-treated $\mathrm{HfO}_{2}$ as a gate insulator.

are incorporated into $\mathrm{O}$ vacancy sites. ${ }^{2}$ Also, there is another possibility that the change of interfacial-layer thickness results in the differences in CET values. ${ }^{6}$ Thus, the CET can be either increased or decreased by $\mathrm{F}$ treatment, depending on $\mathrm{F}$ treatment, conditions.

Figure 1a shows $D_{\text {it }}$ and $V_{\mathrm{FB}}$ values for the pre-F, the post-F (postdeposition F-treated sample), and the untreated $\mathrm{HfO}_{2}$. These samples show almost the same CET values. $D_{\text {it }}$ values of the untreated $\mathrm{HfO}_{2}$ and the post-F were almost the same as 1.3 $\times 10^{11} \mathrm{eV}^{-1} \mathrm{~cm}^{-2}$, while that of the pre-F $\quad\left(D_{\mathrm{it}}=0.8\right.$ $\times 10^{11} \mathrm{eV}^{-1} \mathrm{~cm}^{-2}$ ) was the smallest. Although this is higher than that of previously reported ALD $\mathrm{HfO}_{2}$ from $\mathrm{O}_{3},{ }^{14}$ it is smaller than other previously reported values of $\mathrm{ALD} \mathrm{HfO}_{2}$ thin films using thermal or PE-ALD. ${ }^{15-18}$ The reduction of $D_{\text {it }}$ for the pre-F is attributed to the effective passivation of $\mathrm{Si}$ dangling bonds resulting from $\mathrm{Si}-\mathrm{F}$ bonding formation. ${ }^{7}$ The positive shift of $V_{\mathrm{FB}}$ is due to the negative fixed charge induced by incorporated $\mathrm{F}$ atoms, in agreement with a previous report. ${ }^{19}$ However, we cannot exclude the possibility that $D_{\text {it }}$ also contributes to $V_{\mathrm{FB}}$ shift. The $V_{\mathrm{FB}}$ of post-F was much larger than that of the pre-F sample. The $V_{\mathrm{FB}}$ shift of the post-F is larger than that of the pre-F, implying a larger amount of $\mathrm{F}$ incorporation for the post-F.

Additionally, we measured leakage current densities for these three samples (Fig. 1b). The leakage current density of the pre-F was reduced by three times to $8 \times 10^{-7} \mathrm{~A} / \mathrm{cm}^{2}$ at $-1 \mathrm{MV} / \mathrm{cm}$ compared to that of the untreated $\mathrm{HfO}_{2}\left(2.5 \times 10^{-6} \mathrm{~A} / \mathrm{cm}^{2}\right)$. This leakage current density is comparable to that of previously reported ALD $\mathrm{HfO}_{2}$ using $\mathrm{O}_{3}$ as a reactant with the same CET. ${ }^{20}$ In contrast, the
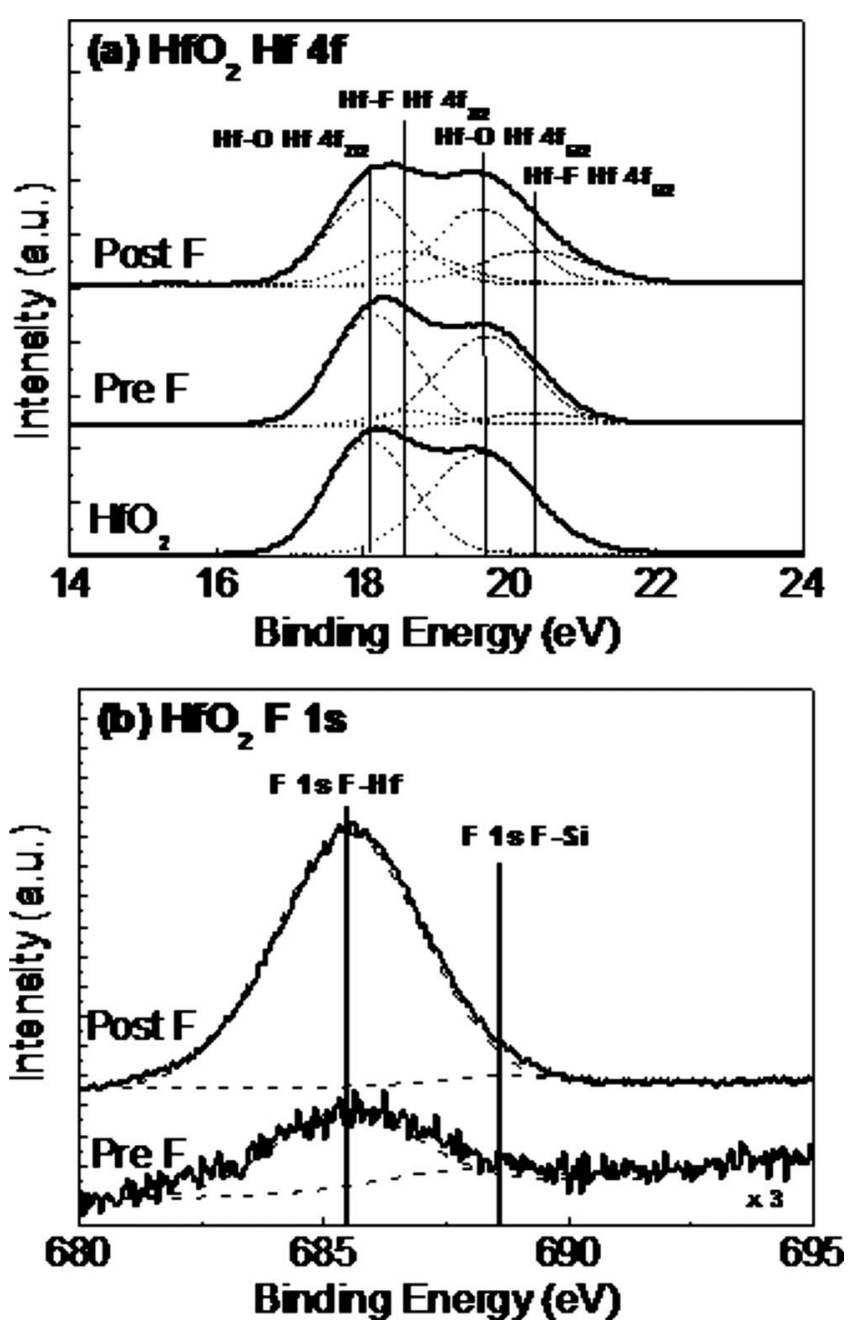

Figure 2. (a) $\mathrm{Hf} 4 \mathrm{f}$ and (b) $\mathrm{F} 1 \mathrm{~s}$ XPS spectra of as-deposited $\mathrm{HfO}_{2}$ and fluorine-treated $\mathrm{HfO}_{2}$.

leakage current density of the post-F was increased to 8 $\times 10^{-4} \mathrm{~A} / \mathrm{cm}^{2}$ at $-1 \mathrm{MV} / \mathrm{cm}$, which is 2 orders of magnitudes higher than that of the pre-F.

Figure 2 shows XPS spectra of the three samples near the binding-energy region of $\mathrm{Hf} 4 \mathrm{f}$ orbital. By deconvolution, it is observed that the spectrum of the untreated $\mathrm{HfO}_{2}$ is composed of $\mathrm{Hf}-\mathrm{O}$ bonding peaks, while additional Hf-F bonding peaks ${ }^{4}$ are clearly seen for the pre- and post-F, indicating that the $\mathrm{F}$ incorporation was effectively achieved by $\mathrm{CF}_{4}$ plasma treatment for both cases. The larger Hf-F peak area of the post-F indicates that the amount of $\mathrm{F}$ incorporation is larger for the post-F, in agreement with the larger positive $V_{\mathrm{FB}}$ shift shown in Fig. 1a. Figure $2 \mathrm{~b}$ shows the $\mathrm{F} 1 \mathrm{~s}$ spectra for the pre- and post-F samples. For the same plasma exposure time, two F-treated samples showed the different $\mathrm{F}$ atomic concentrations as 3 and $23 \%$ for pre- and post-F by XPS analysis, respectively. F 1 s spectrum of the post-F sample is entirely composed of a single F-Hf peak at $685.5 \mathrm{eV}^{3}$, while a small $\mathrm{F}-\mathrm{Si}$ peak is also observed for the pre-F. However, almost no F-Si peak was observed for the post-F sample. This is attributed to the low treatment temperature, which inhibits the diffusion of $\mathrm{F}$ atoms during treatment.

The electronic structure changes by $\mathrm{F}$ treatment were investigated using synchrotron XPS (Fig. 3). After deconvolution, the valence-band spectra of the untreated $\mathrm{HfO}_{2}$ in Fig. 3a shows $\pi$ bonding $\left(e_{\mathrm{g}}\right.$ of $\mathrm{Hf} 5 \mathrm{~d}_{3 / 2}$ and $\left.\mathrm{O} 2 \mathrm{p}\right)$ around $6 \mathrm{eV}$ and $\sigma$ bonding $\left(t_{2 \mathrm{~g}}\right.$ of $\left.\mathrm{Hf} 5 \mathrm{~d}_{5 / 2}\right)$ around $8.2 \mathrm{eV}$, in agreement with previous reports. ${ }^{21,22}$ The valence-band maxima of the untreated $\mathrm{HfO}_{2}$ and the pre-F were 

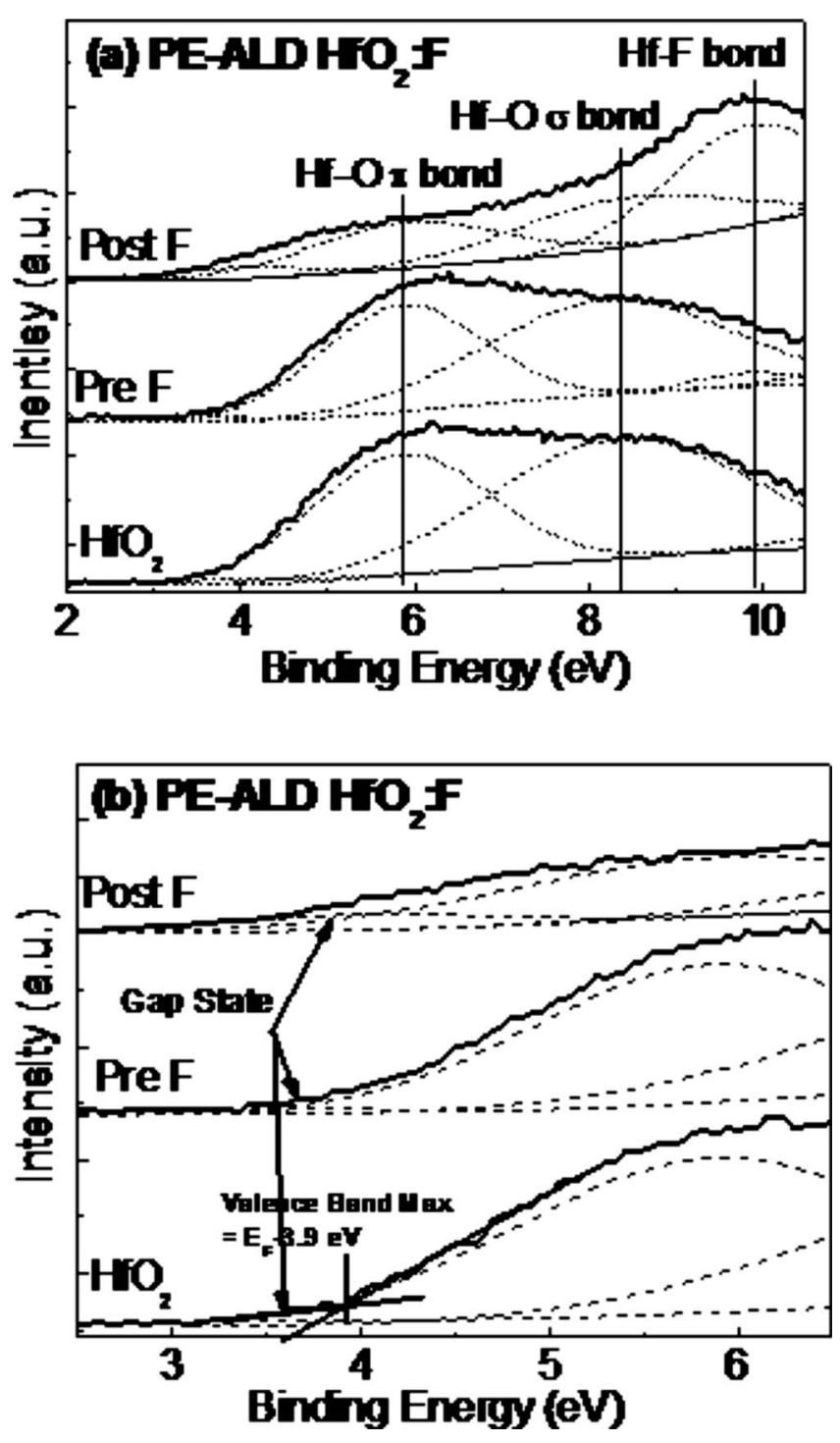

Figure 3. (a) Valence band and (b) magnified valence-bandedge spectra of $\mathrm{HfO}_{2}$ and fluorine-treated $\mathrm{HfO}_{2}$.

determined to be about $3.90 \mathrm{eV}$ by a simple intersection method, as shown in Fig. $3 b^{23}$ Figure 4 shows $\mathrm{O} \mathrm{K}_{1}$ NEXAFS spectra showing conduction band-edge states of the three samples. All spectra show features from $e_{\mathrm{g}}$ orbital around $532 \mathrm{eV}$ and $t_{2 \mathrm{~g}}$ orbital around $536 \mathrm{eV}^{21}$ The conduction bandedge for the post-F appears to remain the same as the untreated $\mathrm{HfO}_{2}$, although broadening of the tail for NEXAFS spectra around $530-531 \mathrm{eV}$ is observed.

\section{Discussion}

Figure 3 shows that the valence-band spectra of the post-F were changed significantly by $\mathrm{F}$ treatment with a new peak around $10 \mathrm{eV}$ from the Fermi level. Previous first-principles calculations demonstrated that the density of state of incorporated $\mathrm{F}$ in $\mathrm{HfO}_{2}$ exists at $6 \mathrm{eV}$ lower than the valence-band maximum. ${ }^{11,24}$ Thus, the new peak was assigned to the peak from incorporated F. In addition, the intensities of Hf-O $\pi$ and $\sigma$ bonding peaks were significantly decreased for the post-F, indicating a decrease in the number of $\mathrm{Hf}-\mathrm{O}$ bonds caused by the formation of Hf-F. Meanwhile, we observed small but significant presences of gap states above the valence-band maximum point for all samples. These are attributed to the presence of gap states, previously reported for $\mathrm{HfO}_{2}$ by Lucovsky et al. ${ }^{21} \mathrm{~A}$ first-principles calculations on the electronic structure of $\mathrm{HfO}_{2}$ has

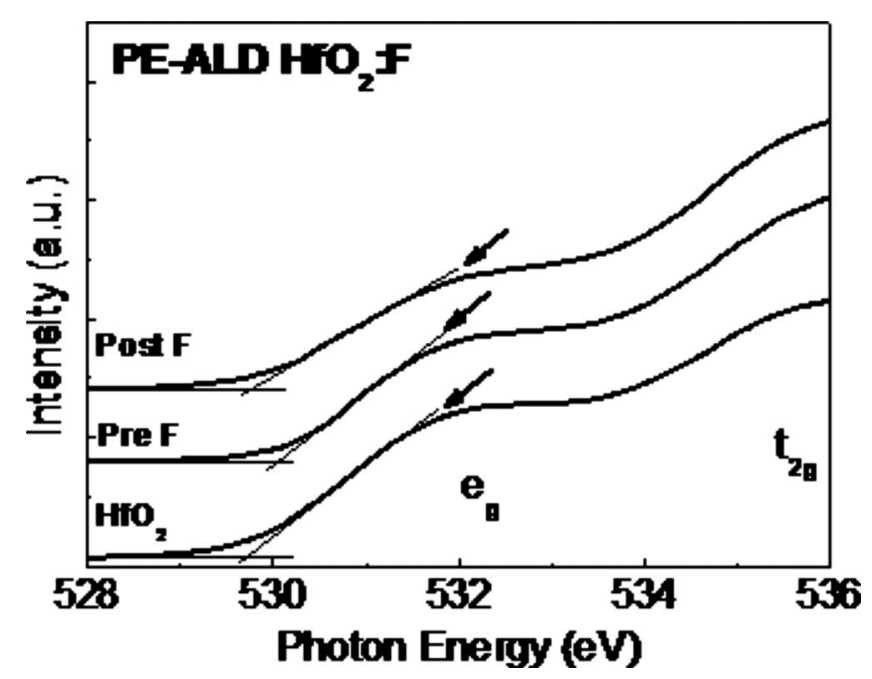

Figure 4. NEXAFS spectra of $\mathrm{HfO}_{2}$ and fluorine-treated $\mathrm{HfO}_{2}$.

shown that various defect states such as $V_{\mathrm{o}}$ (oxygen vacancies) and oxygen interstitial atoms are responsible for these gap states. ${ }^{25}$ Figure $3 b$ shows that these gap states significantly increased for the post-F, while almost no change was observed for the pre-F compared to the untreated $\mathrm{HfO}_{2}$.

In Fig. 4, broadening of the tail in NEXAFS spectrum is observed for the post-F at around 530-531 eV. Because the NEXAFS spectra show the absorption energy of electron transition from the core level to the conduction band, the tail broadening of the conduction band indicates the existence of defect states in the bandgap close to the conduction bandedge. ${ }^{26}$ Thus, similar to the valence bandedge, the post-F has a higher gap state density under the conduction-band minimum than the pre-F and untreated $\mathrm{HfO}_{2}$. This is in agreement with the previous first-principles calculations, ${ }_{5}$ proposing the generation of the gap state by excess $\mathrm{F}$ atoms near the $\mathrm{Hf}-\mathrm{O}$ molecules due to the higher electronegativity of $\mathrm{F}$ than $\mathrm{O}$. Meanwhile, the conduction-band minimum of the pre-F sample was shifted to about $0.4 \mathrm{eV}$ compared to the untreated sample. This implies that the conduction-band minimum level of the pre-F sample was raised by $\mathrm{F}$ predeposition treatment.

Recently, the conduction-bandedge shift to a higher energy level by $\mathrm{F}$ implantation of $\mathrm{HfO}_{2}$ was reported, based on leakage-current measurement. ${ }^{27}$ Similarly, we fitted the leakage-current data for the untreated and the pre-F samples using the Poole-Frenkel (P-F) conduction model (Fig. 5). The leakage current in the P-F conduction regime can be represented by the following equation

$$
J \propto E \exp \left[\frac{q\left(-\Phi_{\mathrm{t}}\right)+\sqrt{q E / \pi \varepsilon_{\mathrm{i}}}}{k_{\mathrm{B}} T}\right]
$$

where $\varphi_{\mathrm{t}}$ is the energy level of a trap with respect to the conduction band of the gate oxide, $E$ is the effective electric field across the insulator, and $\varepsilon_{\mathrm{i}}$ is the high-frequency dielectric constant. Thus, the $\ln \left(J_{\text {leakage }} / E\right)$ vs $E^{1 / 2}$ graph should have a linear relationship with the P-F regime. The leakage-current data for the pre-F and untreated $\mathrm{HfO}_{2}$ indicate that the P-F conduction regime extends to a higher voltage for the pre-F $(6.25 \mathrm{MV} / \mathrm{cm})$ compared to the untreated $\mathrm{HfO}_{2}(5.25 \mathrm{MV} / \mathrm{cm})$, confirming the observation from NEXAFS. On the contrary, the post-F sample showed P-F conduction for the entire range of applied voltages, which is attributed to the large gap states (data not shown).

In addition, the slope of the tail for the NEXAFS spectrum of the pre-F was decreased compared to the untreated $\mathrm{HfO}_{2}$. For the pre-F sample, it is inferred that the defect state under the conduction bandedge is reduced by $\mathrm{F}$ treatment. The reduction of the defect state is attributed to passivation by $\mathrm{F}$ incorporation. ${ }^{12}$ Thus, the decrease in 


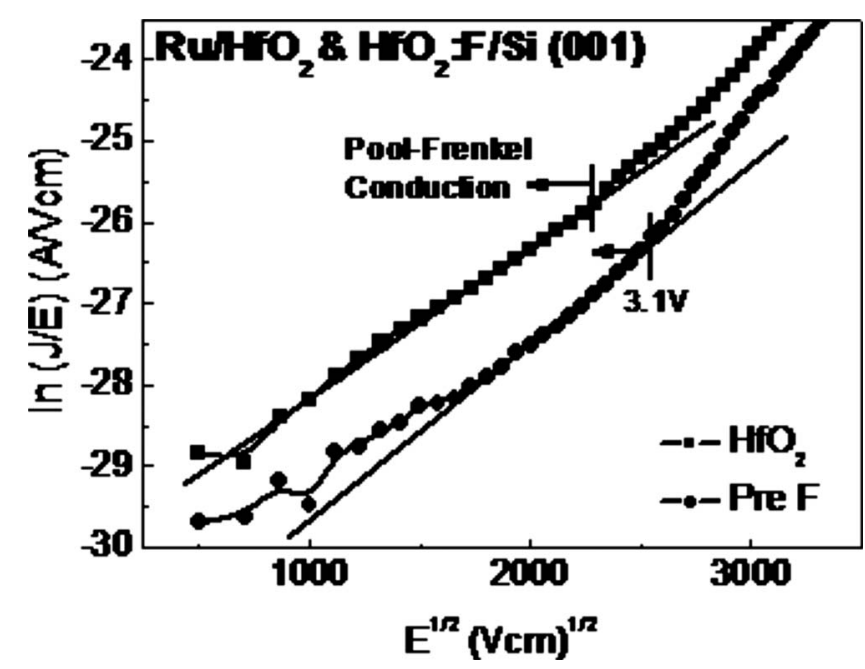

Figure 5. The $\operatorname{In}(J / E)$ vs $E 1 / 2$ for the MOS capacitors shown. The straight line indicates that conduction occurs through the P-F mechanism. The post-F sample was not shown in this data, because the conduction mechanism is entirely P-F conduction by high defect concentrations.

leakage current for the pre-F sample is caused by the passivation of the defect state as well as an increase in the conduction-band minimum in spite of the same CET of the pre-F sample to the CET of the untreated $\mathrm{HfO}_{2}$. In contrast, the post-F-treated sample shows large leakage currents due to a large number of defect states, which is probably due to the excess of $\mathrm{F}$ incorporation. ${ }^{5}$

\section{Conclusions}

The effects of $\mathrm{F}$ treatment for the three different F-treatment profiles and concentrations have been investigated. An optimum amount of $\mathrm{F}$ near the interface improved electrical properties such as CET, $D_{\text {it }}$, and leakage current. From XPS and NEXAFS data obtained by synchrotron radiations, it was found that $\mathrm{Si}-\mathrm{F}$ bonding formation at interface and defect state passivation can improve the electrical properties. But, post-F treatment could not reduce interface state density as well as enhance leakage currents, because it increased the gap state resulting from the excess of $\mathrm{F}$ incorporations. Thus, the optimum level of $\mathrm{F}$ incorporation near the interface is necessary to obtain good electrical properties for future microelectronic devices.

\section{Acknowledgments}

XPS and NEXAFS were analyzed at the Pohang Accelerator Laboratory on beamline 4B1. This work was supported by the Korea Research Foundation (MOEHRD, KRF-2008-005-J00501, KRF2007-331-D00243), and Korea Ministry of Commerce, Industry and Energy (System IC 2010, Commercialization Program of Nano Pro- cess Equipments). Also, this work was supported by the Korea Science and Engineering Foundation (KOSEF) (grant no. R01-2007000-20143-0 and no. 2007-02864). W.J.M. was financially supported by the Brain Korea 21 project 2008.

Pohang University of Science and Technology assisted in meeting the publication costs of this article.

\section{References}

1. H. H. Tseng, P. J. Tobin, E. A. Hebert, S. Kalpat, M. E. Ramon, L. Fonseca, Z. X Jiang, J. K. Schaeffer, R. I. Hegde, and D. H. Triyoso, Tech. Dig. - Int. Electron Devices Meet., 2005, 696

2. M. Inoue, S. Tsujikawa, M. Mizutani, K. Nomura, T. Hayashi, K. Shiga, J. Yugami, J. Tsuchimoto, Y. Ohno, and M. A. Y. Yoneda, Tech. Dig. - Int. Electron Devices Meet., 2005, 413.

3. K. Seo, R. Sreenivasan, P. C. McLntyre, and K. C. Saraswat, Tech. Dig. - Int Electron Devices Meet., 2005, 4.

4. W. C. Wu, C. S. Lai, J. C. Wang, J. H. Chen, M. W. Ma, and T. S. Chao, J. Electrochem. Soc., 154, H561 (2007).

5. J.-H. Ha, K.-I. Seo, P. C. McIntyre, K. C. Sarawat, and K. Cho, Appl. Phys. Lett., 90, 112911 (2007).

6. P. J. Wright and K. C. Saraswat, IEEE Trans. Electron Devices, 36, 879 (1989).

7. M. Chang, M. Jo, H. Park, H. Hwang, B. H. Lee, and R. Choi, IEEE Electron Device Lett., 28, 21 (2007).

8. C. S. Lai, W. C. Wu, J. C. Wang, and T. S. Chao, Appl. Phys. Lett., 86, 222905 (2005).

9. C. S. Lai, W. C. Wu, T. S. Chao, J. H. Chen, J. C. Wang, L.-L. Tay, and N. Rowell, Appl. Phys. Lett., 89, 072904 (2006).

10. C. S. Lai, K. M. Fan, H. K. Peng, S. J. Lin, C. Y. Lee, and C. F. Ai, Appl. Phys. Lett., 90, 172904 (2007)

11. W. Chen, Q.-Q. Sun, S.-J. Ding, D. W. Zhang, and L.-K. Wang, Appl. Phys. Lett., 89, 152904 (2006).

12. K. Tse and J. Robertson, Appl. Phys. Lett, 89, 142914 (2006).

13. W. J. Maeng and H. Kim, Appl. Phys. Lett., 91, 092901 (2007).

14. J. Park, T. J. Park, M. Cho, S. K. Kim, S. H. Hong, J. H. Kim, M. Seo, C. S Hwang, J. Y. Won, R. Jeong, et al., J. Appl. Phys., 99, 094501 (2006).

15. K.-I. Seo, D.-I. Lee, P. Pianetta, H. Kim, K. C. Saraswat, and P. C. McIntyre, Appl. Phys. Lett., 89, 142912 (2006).

16. S. Duenas, H. Castan, H. Garcia, J. Barbolla, K. Kukli, J. Aarik, M. Ritala, and M. Leskela, Microelectron. Reliab., 45, 949 (2005).

17. S. Chatterjee, Y. Kuo, J. Lu, J. Y. Tewg, and P. Majhi, Microelectron. Reliab., 46, 69 (2006).

18. S. Duenas, H. Castan, H. Garcia, J. Barbolla, K. Kukli, J. Aarik, and A. Aidla, Semicond. Sci. Technol., 19, 1141 (2004).

19. C. S. Lai, W. C. Wu, K. M. Fan, J. C. Wang, and S. J. Lin, Jpn. J. Appl. Phys., Part 1, 44, 2307 (2005)

20. M. Cho, D. S. Jeong, J. Park, H. B. Park, S. W. Lee, T. J. Park, C. S. Hwang, G. H. Jang, and J. Jeong, Appl. Phys. Lett., 85, 5953 (2004).

21. G. Lucovsky, H. Seo, L. B. Fleming, J. Luning, P. Lysaght, and G. Bersuker, Surf. Sci., 601, 4236 (2007).

22. H. R. Huff and D. C. Gilmer, High Dielectric Constant Materials: VLSI MOSFET Applications, Springer, New York (2005).

23. O. Renault, N. T. Barrett, D. Samour, and S. Quiais-Marthon, Surf. Sci., 566, 526 (2004).

24. Q.-Q. Sun, W. Chen, S.-J. Ding, M. Xu, H.-L. Lu, H.-C. Lindh-Rengifo, D. W. Zhang, and L.-K. Wang, Appl. Phys. Lett., 90, 142904 (2007).

25. A. S. Foster, F. L. Gejo, A. L. Shluger, and R. M. Nieminen, Phys. Rev. B, 65 , 174117 (2002).

26. D.-Y. Cho, J.-M. Lee, S. J. Oh, H. Jang, J. Y. Kim, J. H. Park, and A. Tanaka, Phys. Rev. B, 76, $165411(2007)$.

27. W. C. Wu, C. S. Lai, T. M. Wang, J. C. Wang, C. W. Hsu, M. W. Ma, and T. S. Chao, Electrochem. Solid-State Lett., 11, H15 (2008). 